\title{
Ergonomics of a Custom Made Solar Electric Car
}

\author{
Karam Siva Bhushan Reddy, M. Vijaya Kini, Amol Grover, and P. S. Sujay
}

\begin{abstract}
A 1:1 Ergonomic apparatus was designed and fabricated for a solar electric passenger car in compliance with the regulations prescribed in the document 'World Solar Challenge - Rules and Regulations 2013' and the road rules of the country. The apparatus has adjustable cabin dimensions to incorporate various body dimensions that are required for a passenger car. Several ergonomic parameters were used to obtain an optimum design. Importance was given to safety, human machine interface and comfort. The Ergonomics features were designed, analyzed and validated using the solid modeling software CATIA to make a prototype to incorporate the people within the range of 95 percentile male to 5 percentile female.
\end{abstract}

Index Terms-Cabin, ergonomics, solar car, world solar challenge (WSC), catia.

\section{INTRODUCTION}

Ergonomics is an aspect which is crucial in any car and hence requires utmost attention. It is an interface where human and machine interacts. It is important to note that vehicle packaging is meant to provide suitable space for people and parts of the vehicle; human factor consideration is a must for the integration of the total design [1]. The cockpit informs the driver of the vehicle's condition and executes the driver's commands [2].One should also make sure that the interior equipment doesn't distract the driver's attention [3] while driving and are situated in places that will not damage the passengers in case of an accident. Driver comfort and accessibility of vehicle controls during car operation maximizes the performance capabilities of the car [4], [5].

This study attempts to design a cabin that can accommodate a range of drivers within the stipulated rules and regulations being safety and comfort outmost priority. The important dimensions in the ergonomic apparatus are the seat rest angle, the seat base angle, the steering location, the brake pedal location and the position of the hip point. The ergonomic apparatus was designed and built keeping each of the above dimensions adjustable. Data for all these parameters was compiled and analyzed to obtain the optimum angles and position of seat, steering, brake pedal and accelerator pedal location.

Manuscript received October 31, 2014; revised February 2, 2015 Funding for this solar car project-Solar Mobil Manipal (www.solarmobilmanipal.in) was provided by Ministry of Small and Medium Scale Enterprises and Manipal University.

Karam Siva Bhushan Reddy, Amol Grover, and P. S. Sujay are with the Department of Mechanical and Manufacturing Engineering, Solar Mobil Manipal, Manipal Institute of Technology, Manipal 576104, Karnataka, India (e-mail: siva.k@learner.manipal.edu, sujay.paratala@gmail.com, amo193grover@yahoo.co.in).

M Vijaya Kini is with Faculty of Mechanical and Manufacturing Engineering, Manipal Institute of Technology, Manipal 576104, Karnataka, India (e-mail: mv.kini@manipal.edu).

\section{Methodology}

Several models of commercial cars were studied for their ergonomic features. An extensive ergonomic research was done in order to obtain cabin dimensions for a passenger vehicle under WSC-Rules and Regulations 2013 along with road rules of the country. Ergonomics and Analysis, Human Builder and Human posture modules of CATIA were used to obtain a preliminary design of the seat and driver's posture Human builder was used to determine the viewability of the driver, height of the car and also for fixing the position of steering assembly (see Fig .1).

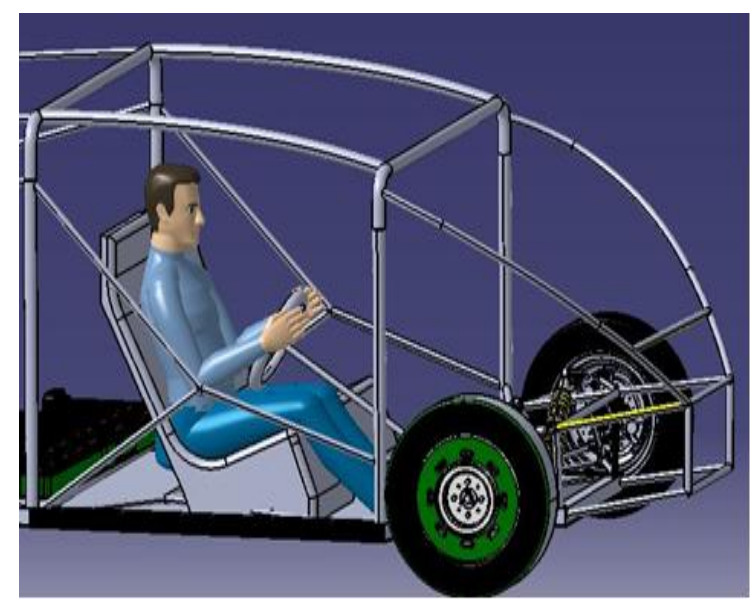

Fig. 1. Ergonomic setup designed in CATIA.

The angles and position were limited over a certain range, keeping safety and comfort in mind. Initial design was converted to a 1:1 prototype using ply wood. Wood was considered as it was easily available, affordable and easy to work with. Steel racks were used to provide a rigid frame to get a basic idea about the car's body. The average height was considered to be 5' 11 " or 95th percentile male as per WSC regulations.

Following objectives were set for the optimum performance:

1) Seat back rest Angle

- Driver remains at a comfortable position

- Centre of gravity remains as low as possible

- Proper view and accessibility

2) Seat Base Angle

- To provide thigh support while operating pedals

- To provide proper access to brake pedals

3) Steering Location

- To provide proper grip to the driver

- Driver can turn the steering wheel without much strain in hands.

4) Proper width of the cabin to accommodate seat and driver.

5) Proper positioning of pedal assembly and steering wheel 
location. The heel location must be below the hip point for cars under the Cruiser Class.

6) To get the height of the car at regular intervals in order to get best aesthetic look.

7) Positioning of the front roll bar or A - pillars.

8) Positioning of the roll bar or the $\mathrm{B}$ - pillars.

And also for the Cruiser Class vehicles, the head space must be in compliance with the LK Seating rules of Australia. No structural members must be within the shaded area as shown in Fig. 2 below. All measurements are taken from the hip point.

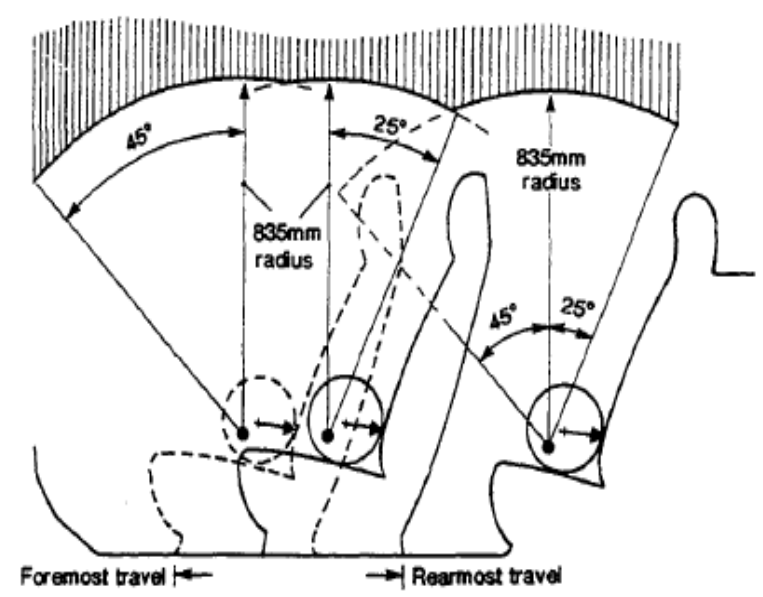

(a)

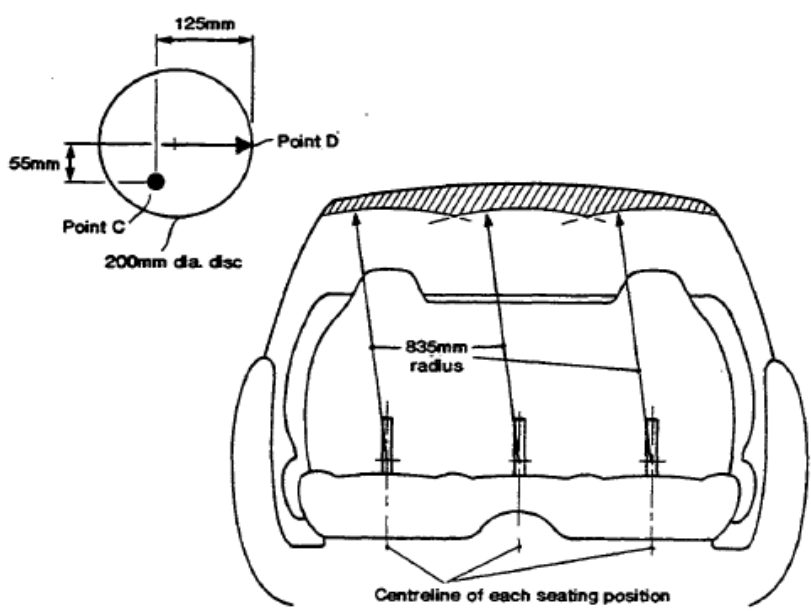

(b)

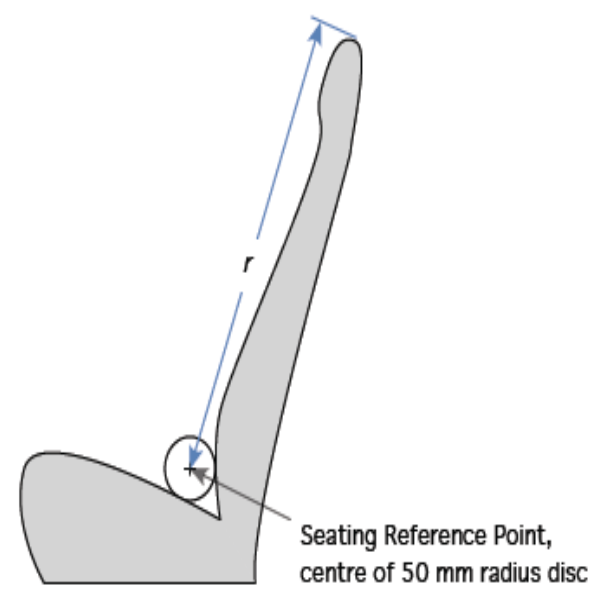

(c)

Fig. 2. No structural members must be within the shaded area.

\section{APPARATUS}

The prototype apparatus was built so that subjects can sit in an adjustable cabin (see Fig. 3).

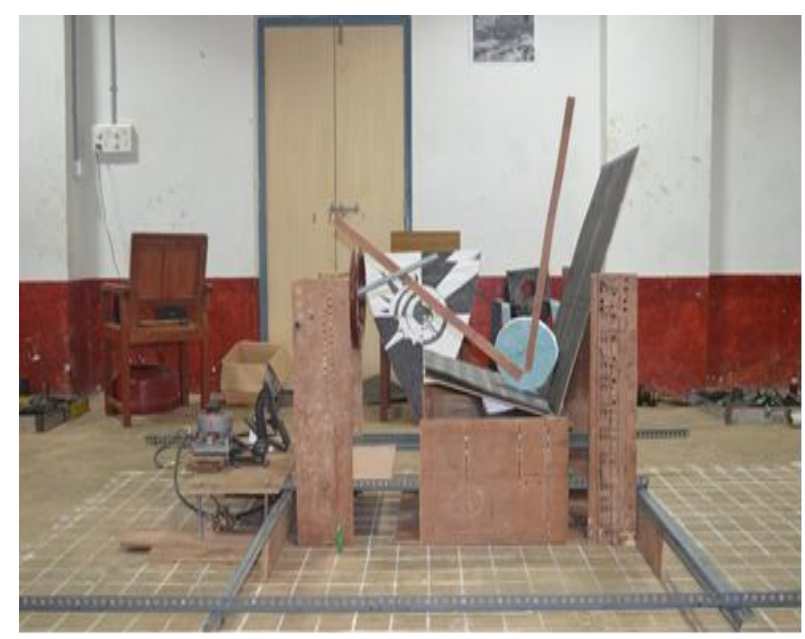

Fig. 3. Ergonomic apparatus.

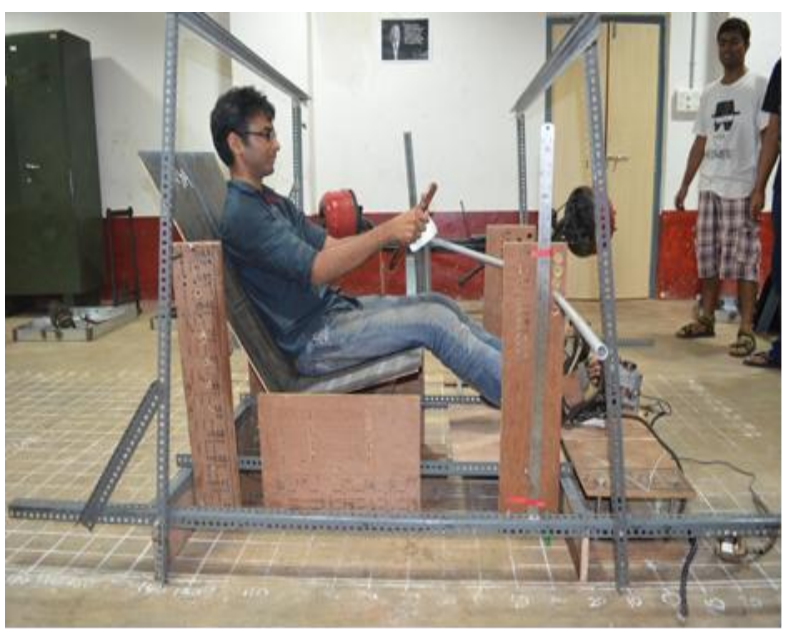

Fig. 4. Iteration being carried out on Ergonomic apparatus.

Seat rest angle, seat base angle, steering location, brake pedal, accelerator pedal, height of hip point $(\mathbf{H})$ and lowest point of the seat $(\mathbf{R})$ are adjustable in the apparatus. Two boards of hinged ply wood were used as supports for back and base. Two back supports with drilled holes were used to vary the seat rest angle. To vary the seat base angle two supports were put underneath the seat. Two side supports with large number of drilled holes were used to vary the H-point and the R-point. This part was important because with the change in H-point every other variable changes. For every fixed H-point other variables were adjusted and checked for the comfort and safety of the driver. Even the viewing capacity and head clearance changes considerably with small changes to these points, hence many iterations were carried out to improve the performance of these parameters.

The Pedal assembly and steering location were adjusted for a fixed seat angle to maintain the comfort of the driver. The process was repeated for different seat angles, to obtain a desirable position for the driver. Tests were carried out to obtain the ideal seating position for 95 percentile male. The iterations and analysis were carried out on ergonomics apparatus as shown in Fig. 4. 


\section{DATA COMPLETION}

The entire data was compiled into a tabular form (see Table I).

TABLE I: COMPILATION OF THE DATA

\begin{tabular}{|l|l|l|l|l|l|l|l|l|}
\hline Name & $\begin{array}{l}\text { Height } \\
\text { (feet) }\end{array}$ & $\begin{array}{l}\text { H point } \\
\text { (in mm) }\end{array}$ & $\begin{array}{l}\text { Seat } \\
\text { Angle } \\
\text { (degree) }\end{array}$ & $\begin{array}{l}\text { Thigh } \\
\text { Angle } \\
\text { (degree) }\end{array}$ & $\begin{array}{l}\text { H } \\
\text { point } \\
\text { to } \\
\text { dash } \\
\text { (cm) }\end{array}$ & $\begin{array}{l}\text { Width } \\
\text { of } \\
\text { legs } \\
\text { (cm) }\end{array}$ & $\begin{array}{l}\text { Knee } \\
\text { width } \\
\text { (cm) }\end{array}$ & $\begin{array}{l}\text { Steering } \\
\text { wheel } \\
\text { height } \\
\text { (cm) }\end{array}$ \\
\hline Siva & $5^{\prime} 10^{\prime \prime}$ & $(1200,240,420)$ & 26 & 25 & 94 & 12 & 25 & 30 \\
\hline Sooriya & $5^{\prime} 9^{\prime \prime}$ & $(1200,240,420)$ & 28 & 23 & 95 & 12 & 25 & 29 \\
\hline Siddhanth & $6^{\prime} 1^{\prime \prime}$ & $(1200,240,420)$ & 29 & 24 & 93 & 12 & 24 & 32 \\
\hline Nitin & $6^{\prime}$ & $(1200,240,420)$ & 29 & 24 & 94 & 12 & 26 & 31 \\
\hline Nived & $5^{\prime} 10^{\prime \prime}$ & $(1200,240,420)$ & 30 & 25 & 92 & 12 & 25 & 30 \\
\hline
\end{tabular}

\section{NOVEL IDEAS AND INNOVATION}

After fixing $\mathrm{H}$ point every other parameter was kept variable so that a range of possibilities were available and the best design could be obtained after proper analysis and iterations.

- The low hip point also leads to leg line of action inclined at a small angle to the horizontal, which leads to the pedal axis being inclined at a greater angle to the vertical. This leads to more horizontal pedal thereby increasing the comfort level of the driver.

- Dash board was strategically placed in center between the driver and front passenger, this provided room for leg space and comfortable exit.

- A 1:1 PVC chassis was made so that seat location could be fixed as per our design, giving a realistic idea about the interaction between human and car.

- Significant amount of clearance was provided (14inch) as crumple zone with regards to the safety of the driver, also provided was some room for chassis members which enhanced the overall safety of the passengers.

\section{SElection OF SubJects}

The primary criterion for selection of driver was their driving skills, based on which five members were selected. Most of the members were of different physique. The average height was found to be 5' 11 ' ' which is close to the guidelines recommended by WSC regulations for 95 th percentile male.

\section{RESUlTS AND DisCUSSIONS}

The outcome of the ergonomic study is as follows:

- Optimum position of $\mathrm{H}$ point to be 47 inch

- Seat base 25 degree angle

- Seat back rest 30 degree angle

- Location of steering wheel

- pedal assembly location

- Seat, Accelerator pedal and brake pedal location.

- Packaging of the components

- Distance of dash board from drivers

Since the drivers should have a good grip over the steering wheel at a distance that gives them the best mechanical advantage, the distance from the dash to drivers H-point was first considered. This distance determines the horizontal location of steering wheel In order to achieve best steering wheel angle and dash height, the maximum dash height obtained was $20 \mathrm{inch}$. As the regulations mandate that the driver should be able to see at least 4 meters. Therefore, by fixing it the other dimensions were calculated using simple geometry. The location of the shortest driver's eyes from $\mathrm{H}$ point was measured, this is critical for designing the cabin. But this doesn't account for the visibility that the body of the car will occupy. The body will slope downwards to the nose of the car but would remain above the line of sight. To account for this two inches clearance was given. Adjustable pedals were designed to accommodate variation in body shape of drivers.

A Poly Venial Chloride (PVC) chassis (1:1scale) was fabricated to simulate the exact seating location and test the human-machine interaction (see Fig. 5).

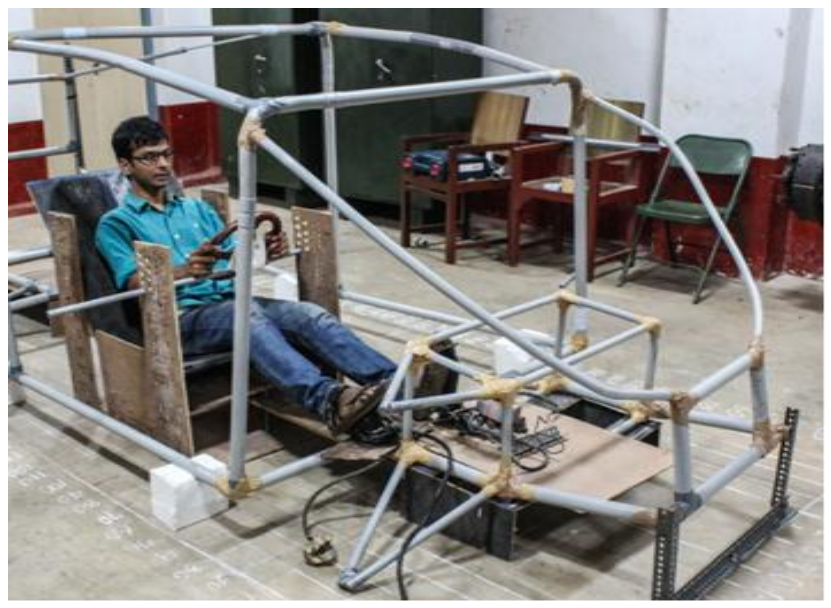

Fig. 5. PVC chassis with ergonomic apparatus.

The following observations were made:

- The assembly of the seat, brake pedal, accelerator pedal and steering location with mounting on the chassis were tested and the interference was checked.

- The suspension system was fabricated using the PVC pipes so that exact location of steering assembly and pedal assembly could be determined which in turn helped in fixing the location of seat.

- Due to curved windshield members, the view ability was given special importance, so that the driver could have uninterrupted view up to four meters ahead of the car at a height of 0.75 meters above and below the eye level.

- This gave a close estimate of the clearance between driver and top of the car which is important in case of roll over of a car and thus the safety of the driver.

- This helped in determining the location of height of the car at regular intervals, door handle, side windows and side mirrors.

\section{CONCLUSION}

The ergonomics apparatus data provided accurate cabin dimensions for the subjects. Design iterations of the cabin were tested with the subjects by adjusting the apparatus accordingly and validation was done using PVC chassis.

The ergonomic data obtained was evaluated and results 
were incorporated in the car. This study has given the best aesthetics, ergonomic, safety and roadworthiness of the car. Feedback obtained from the drivers indicated that the car was comfortable for driving.

\section{ACKNOWLEDGMENT}

Funding for this solar car project- Solar Mobil Manipal (www.solarmobilmanipal.in) was provided by Ministry of Small and Medium Scale Enterprises and Manipal University.

\section{REFERENCES}

[1] M. G. P. Fernandes, "Cockpits: design and development," $S A E$ Journals, 1992.

[2] G. F. Beal, "Making the cockpit practical for pilot," SAE Journals, vol. 53 , no. 8, 1945.

[3] S. Gerald, "The design eye reference point," SAE Journals, 1987.

[4] B. Jawad, "Formula SAE race car cockpit design an ergonomic study," SAE Journals, 2000.

[5] M. Fabian and G. Fedorko, "Current trends in process of design and production of automobiles," Transport and Logistics, no. 9, pp. 142-149, 2005.

[6] Ergonomické Analýzy CATIE. [Online]. Available: http://catiadoc.free.fr/online/haaug_C2/haaugbt0100.

[7] D. Whitney, Mechanical Assemblies: Their Design, Manufacture, and Role in Product Development, New York: Oxford Univerzity Press, 2004.

[8] A. Mareš and K. Senderská, "Ergonomical modules of catia and their using," Journal of Safety Research and Applications JOSRA, vol. 2, 2011.

[9] Bodywork for a Competition Formula Vehicle. [Online]. Available: http://www.jeromearul.com/FSAE

[10] Z. Mohamed and R. M. Yusuff, "Automotive ergonomics: Passenger cars interior dimension parameters and comfort," in Proc. the ICE2007 International Conference on Ergonomics, 2007, pp. 1-4.

[11] A. Goh. Cab Design and Control. [Online]. Available: http://www.coroflot.com/livesteel/cab-design-control

[12] J. Rix, André Stork "Combining ergonomic and field-of-view analysis using virtual humans," in Proc. the International Conference on Design and Manufacturing (IConDM 2013), pp. 622-631, 2013.

[13] A. Seidl, "RAMSIS: A new CAD-Tool for ergonomic analysis of vehicles developed for the german automotive industry," Tecmath GbmH, 1997

[14] U. Jasnoch, B. Anderson, M. Koch, and J. Rix, "Beyond digital mock-ups: Human aspects in new products," in Proc. the Autofactt, USA, 1997.

[15] Car Body Design, Automotive Design and Engeneering. [Online]. Available: http://www.carbodydesign.com.

[16] Ergonomics in Automotive Industry. [Online]. Available: http://www.ergoworld.com/ergonomics-industryautomotive.html.

[17] Ergonomics and Anthropometrics. [Online]. Available: http://www.cardesignonline.com/design/ergonomics/index.php

[18] B. Peacock and W. Karwowski, Automotive ergonomics, Taylor and Francis, London, 1993
[19] A. Cichański and M. Wirwicki, "Ergonomics analysis of anthropo-technical systems in the environment of catia program," Journal of Polish Cimac, 2003.

[20] Research: Driver And Passenger Ergonomics. [Online]. Available: http://mreed.umtri.umich.edu/mreed/research_ergonomics.html

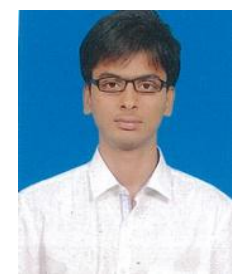

Sivabhushan Reddy was born in 1993 . He received his BE in mechanical and manufacturing at Manipal Institute of Technology. He is the co-founder and the head of SolarMobil Manipal. His research interests include product development, supply chain and operations management.

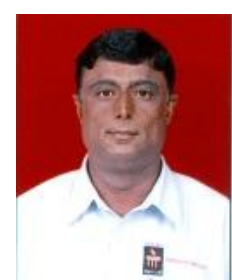

M. Vijaya Kini was born in 1965 . He is an associate professor at the Department of Mechanical and Manufacturing Engineering, Manipal Institute of Technology, Manipal. He obtained his undergraduate degree from Mangalore University, India, in 1986. he is specializing in mechanical engineering and the post graduate degree in engineering management from the Mangalore University, India, in 1994. He is specialized in composite materials for his doctoral program from the Manipal University, Manipal in 2009. His research interests include natural fibre composites and fully degradable composite.

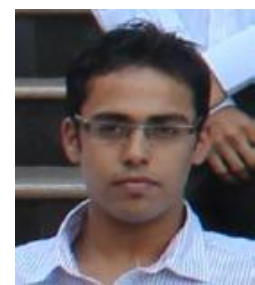

Amol Grover was born in 1994 and is currently pursuing his BTech. degree in mechanical and manufacturing engineering from Manipal Institute of Technology, Manipal. He is working as chassis and aerodynamics head at SolarMobil Manipal Amol's research interests include CAE Manufacturing Techniques and composites.

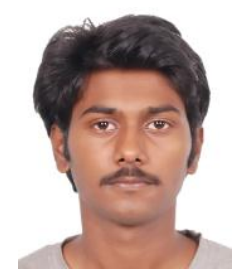

P. S. Sujay was born in 1994 and he is currently pursuing his BTech. degree in automobile engineering from Manipal Institute of Technology, Manipal. His is working as a transmission team member and the head at Solar Mobil Manipal. His research interests include automotive transmission, hybrid vehicles. 